\title{
A Rule-based Dependency Parser for Telugu: An Experiment with Simple Sentences
}

\author{
SANGEETHA P., PARAMESWARI K. \\ \& AMBA KULKARNI
}

\begin{abstract}
This paper is an attempt in building a rule-based dependency parser for Telugu which can parse simple sentences. This study adopts Pạnini's Grammatical (PG) tradition i.e., the dependency model to parse sentences. A detailed description of mapping semantic relations to vibhaktis (case suffixes and postpositions) in Telugu using PG is presented. The paper describes the algorithm and the linguistic knowledge employed while developing the parser. The research further provides results, which suggest that enriching the current parser with linguistic inputs can increase the accuracy and tackle ambiguity better than existing data-driven methods.
\end{abstract}

\section{Introduction}

Parsing is a challenging task especially when languages under investigation are morphologically rich and have relatively freeword order. A parser is an automated Natural Language Processing (NLP) tool that analyses the input sentences based on the grammar formalism adopted in implementation and provides the output in constructed parse trees. The most frequently adopted grammar formalisms include constituency and dependency models. This study adopts the dependency model that has proved to be an efficient model for Indian languages that are morphologically rich with free-word order (Bharati \& Sangal 1993; Kulkarni 2013; Kulkarni \& Ramakrishnamacharyulu 2013; Kulkarni 2019).

Telugu is a South-central Dravidian language with agglutinating morphology and with relatively free word order. Hence, dependency grammar formalism was adopted for this 
study which proved to be useful for other free-word order languages. Apart from grammar formalism, the technique used for the implementation of a parser also stands as equally important. The implementation techniques majorly include grammar-driven or data-driven. The present study uses a grammar-driven technique that handles a wide range of language ambiguities.

This paper discusses various problematic cases in parsing Telugu simple sentence structures which consist of a clause that includes covering constructions such as copula, imperative, passive, dubitative, interrogative, non-nominative subjects, reflexive, and coordinating noun phrases. This paper is the first attempt (to the authors' best knowledge) in building a rule-based parser for Telugu using a dependency framework.

This paper is organized as follows: Section-2 provide the literature survey of parsing in Telugu; section-3 describes the theoretical background for the study involving a discussion on the mapping from kāraka to vibhakti in Telugu, taking insights from PG; Section-4 provides a detailed description on building the current parser, algorithm, and constraints (both local and global); Section-5 provides the evaluation of the rule-based parser and Knowledge-based parser, further discussing the error analysis and some observations; finally, Section-6 concludes and explores the future scope of the study.

\section{Brief Survey}

A few attempts were made in developing a Telugu dependency parser based on data-driven approaches. Some of them include Vempaty Chaitanya, Viswanatha Naidu, Samar Husain, Ravi Kiran, Lakshmi Bai, Dipti Mishra Sharma \& Rajeev Sangal (2010) who discussed issues in parsing various linguistic constructions like copula, genitive, implicit and explicit conjunct, and complementizer constructions. Garapati, Uma Maheshwar Rao, Rajyarama Koppaka \& Srinivas Addanki 
(2012) analysed dative case marker (-ki) with various functions in Telugu in parsing perspective. Kesidi, Sruthilaya Reddy, Prudhvi Kosaraju, Meher Vijay \& Samar Husain (2013) implemented a constraint-based dependency parser for Telugu which was earlier used for languages like Hindi. This parser deals with relations in two different stages wherein stage-1 handles intra-clausal relations and stage-2 handles inter-clausal relations. Kumari, B. V. S., \& Ramisetty Rajeshwara Rao (2015) had developed combinatory categorial grammar supertags using which they claim the enhancement of identification of verbal arguments. Nagaraju, B, N. Mangathayaru \& B. Padmaja Rani 2016), Kumari B. V. S. \& Ramisetty Rajeshwara Rao 2017, Kanneganti S., Himani Chaudhry \& Dipti Misra Sharma (2018) worked on various statistical approaches of parsers. Rama, Taraka \& Sowmya, Vajjala (2018) developed a Telugu treebank using Universal Dependency (UD) tagset with an addition of language-specific tags to handle compound and conjunct verb phrases for Telugu. Gatla (2019) developed a treebank for Telugu which was trained using data-driven parsers, namely, MinimumSpanning Tree (MST) parser and Models and Algorithms for Language Technology (MALT) parser. Nallani, Sneha, Manish Shrivastava \& Dipti Mishra Sharma (2020) expanded treebank by adding language-specific intra-chunk tags to the existing annotation guidelines based on the Pāninian framework. In addition to improving the existing tagset, Nallani, Sneha, Manish Shrivastava \& Dipti Mishra Sharma (2020b), also developed a Telugu parser using a minimal feature Bidirectional Encoder Representations from Transformers (BERT) model providing considerable results. The highest Label Attachment Score (LAS) reported so far has been 93.7\% (Nallani, Sneha, Manish Shrivastava \& Dipti Mishra Sharma 2020) and the approaches have been data-driven. However, the results of the above-mentioned systems prove that there 
should be continuous improvement in the annotated corpus size to improve the results further in data-driven approaches. Hence, the effort in building the parser for Telugu using grammar-driven approaches is attempted in this paper to study its feasibility and advantages.

\section{Theoretical Background}

The dependency model follows the grammatical tradition of dependency, tracing back to Pāninìs grammar. The dependency grammatical model represents the relation between the head and its dependents through directed arcs and arc labels. The relation between content words is marked by dependency relations; functional words are attached to the content words they modify. The parse thus generated is a tree, where the nodes of the parse tree stand for words in an utterance and the link between words represents the relation between pairs of words. All such dependencies in a sentence can either be argument dependencies (subject, object, indirect object, etc.) or modifier dependencies (determiner, noun modifier, verb modifier, etc.). The peculiar feature of the dependency model is to provide syntactico-semantic relations, unlike the other grammar formalisms, which are purely syntactic (Bresnan 1982; Gazdar Gerald, Ewan Klein, Geoffrey k. Pullum, \& Ivan A. Sag, 1985). Based on these syntactico-semantic relations, Bharati Akshar, Dipti Misra Sharma, Samar Husain, Lakshmi Bai, Rafiya Begum \& Rajeev Sangal (2009) have developed a dependency tagset known as Anncora tagset which can be used for almost all major Indian languages. This tagset consists of around 19 fine-grained tags for karaka (K) relations and 25 fine-grained tags for nonkāraka (r) relations. This study adopts the Anncora tagset in order to label dependency relations.

The most common dependency relation in a simple sentence structure includes the dependency between a noun and a verb 
or a noun and a noun. PG uses syntactico-semantic relations called kāraka relations expressed through vibhaktis to capture dependencies between noun-verb and non-kāraka relations to capture noun-noun dependencies. The pāṇinian treatment of $k \bar{a}$ raka relations considers a system of default vibhakti for each relation. This vibhakti assignment is independent of verb semantics. Table-1 provides the default vibhakti for kāraka relations in Telugu. In addition to this, the other tags used for the current parser are listed as part of the Appendix.

\begin{tabular}{|l|l|l|}
\hline Sl.No & käraka Relation & Vibhakti \\
\hline 1 & kartā $(\mathrm{k} 1)$ & -0 \\
\hline 2 & karma $(\mathrm{k} 2)$ & $-n i /-n u$ \\
\hline 3 & karaṇa $(\mathrm{k} 3)$ & $-t \bar{o}$ \\
\hline 4 & sampradāna $(\mathrm{k} 4)$ & $-k i / k u$ \\
\hline 5 & apādāna $(\mathrm{k} 5)$ & $n u M$ di/nuMci/niMci \\
\hline 6 & șașthī $(\mathrm{r} 6)$ & $Y o k k a$ \\
\hline 7 & vișaya-adhikaraṇam $(k 7)$ & $-l \bar{o}$ \\
\hline
\end{tabular}

Table-1: kāraka relations and default vibhaktis in Telugu

Apart from these default vibhaktis, there exist cases of deviation in Telugu in which there is no one-one mapping between the vibhakti and kāraka relation. These deviations arise when the verbs do not follow linguistic generalizations or when a structure is out of the scope of linguistic generalisation. In order to handle these deviations, Panini employs a model wherein he proposes two methods (Preeti 2010) viz.

1. Assigning a different vibhakti

2. Imposing a new kāraka relation

Preeti (2010) summarizes the ways of mapping semantic relations to vibhaktis through kärakas in PG. Consider the following figure: 
Sangeetha P., Parameswari K. \& Amba Kulkarni

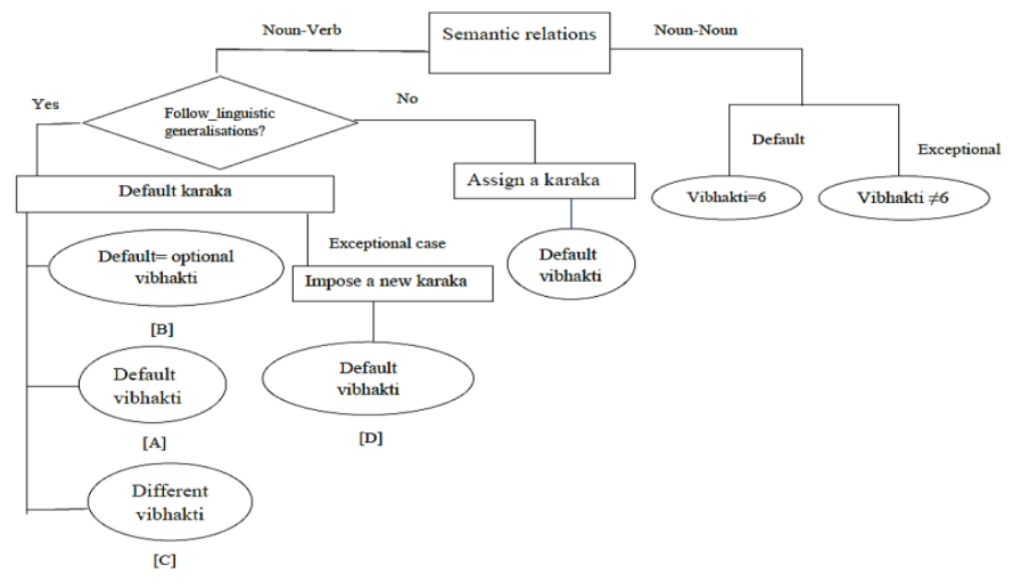

Figure-1 Semantic Relations

Based on fig-1, the semantic relations between noun-verb are divided into the following types:

\subsection{Type-A}

The first type of semantic relation is when the language follows the linguistic generalisation and takes a default kāraka as listed in Table-1. In example (1) as explicated, kartā (k1) and karma (k2) are marked with the default vibhakti i.e $\emptyset$ and $n i$ respectively.

\begin{tabular}{|l|l|l|l|}
\hline 1. & $n \bar{e} n u . \emptyset$ & ravi-ni & cūs- $\bar{a}-n u$. \\
\hline & I.NOM & Ravi-ACC & do-PST-1.SG. \\
\hline & 'I saw Ravi' \\
\hline
\end{tabular}

\subsection{Type-B}

In certain relations, there exist instances of verbs in addition to the default case marking which deviate from the default case marking and assign optionally other case-suffixes as in (2) and (3). The verb серри 'to tell' assigns either vibhakti -ki or -tō to 
A Rule-based Dependency Parser for Telugu:...

express the relation sampradāna (k4) i.e the recipient of an action as in (2).

\begin{tabular}{|l|l|l|l|l|}
\hline 2. & $n \bar{e} n u . \emptyset$ & prakās-ki /-tō & $\bar{a}$ viSayaM & cepp- $\bar{a}-n u$ \\
\hline & I.NOM & Prakash-DAT/ASS & that matter & tell-PST-1.SG \\
\hline & 'I told that matter to Prakash' \\
\hline
\end{tabular}

Similarly, the verb ekku 'to climb' in Telugu, has an expectancy of a noun expressing the location 'to climb'. In this case, the noun is marked either with the vibhakti -nu or mida as in (3).

\begin{tabular}{|l|l|l|l|l|}
\hline 3. & $n \bar{e} n u$ & $\bar{e} n u g u-$ & $\boldsymbol{n u} / \boldsymbol{m} \bar{\imath} d \boldsymbol{a}$ & $e k k-\bar{a}-n u$. \\
\hline & I.NOM & elephant- & ACC/on & climb up-PST-1.SG. \\
\hline \multicolumn{4}{|l}{ 'I climbed an elephant' } \\
\hline
\end{tabular}

\subsection{Type-C}

In certain cases, it is found that a different vibhakti is assigned instead of the default one to indicate a particular semantic relation. For instance, the default vibhakti indicates the source of separation, apādānā i.e. the ablative case as in example (4). However, in the case of mental separation as in (5) where the kartā, $v \bar{a}, \underline{u} u$ 'he' separates himself mentally due to the fear of siMhaM 'lion' which is considered as apadānā in PG but it is realized by the different vibhakti i.e. $-k i$, not by $-n u M d \underline{i}$

\begin{tabular}{|l|l|l|l|l|}
\hline 4. & Ceț $u$ & $n u M d ̣ i ~$ & $\bar{a} k u l u$ & $r \bar{a} \bar{a}-y i$ \\
\hline & Tree & From & Leaves & fall-3.PL \\
\hline \multicolumn{4}{|l}{ 'Leaves fell from the tree' } \\
\hline
\end{tabular}

\begin{tabular}{|l|l|l|l|}
\hline 5. & $v \bar{a} d u$ & siMhāni-ki & bhayapadatāa- $-\underline{u} u$ \\
\hline & $\mathrm{He}$ & lion- & scare-3.SG.M \\
\hline \multicolumn{3}{|l|}{} \\
'He is scared of a lion' \\
\hline
\end{tabular}


Sangeetha P., Parameswari K. \& Amba Kulkarni

\subsection{Type-D}

In certain exceptional cases, it is found that a new käraka is imposed using a default vibhakti. This can be due to the extension of the case relation as explicated in (6) where illu 'home' is the karma to the verb vellu as per PG, however it is marked with the vibhakti $-k i$.

\begin{tabular}{|l|l|l|l|}
\hline 6. & $n \bar{e} n u$ & $i M t i-k i$ & $v e l l-\bar{a}-n u$ \\
\hline & I.NOM & house-DAT & go-PST-1.SG. \\
\hline & \multicolumn{2}{l}{ 'I went home' } \\
\hline
\end{tabular}

The other case as shown in Figure-1 is when the sentence does not follow linguistic generalizations and a new käraka is assigned. We have not come across such cases so far in Telugu; hence no explanation is provided in this paper.

When the semantic relationship is found between noun-noun, non-kāraka relation i.e. sasthhi (the tag ' $\mathrm{r} 6$ ') is expressed by yokka or the default oblique marker or by the vibhakti-ki in certain cases in Telugu as in (7) i.e vādi-ki 'his'.

\begin{tabular}{|l|l|l|l|l|}
\hline 7. & $v \bar{a} d i-k i$ & $k \bar{a} l i-k i$ & debba & tagil-iM-di \\
\hline & He-DAT & Leg-DAT & Wound-NOM & Hit-PST-3.SG.N \\
\hline \multicolumn{4}{|l|}{ 'He got a wound on his leg" } & \\
\hline
\end{tabular}

\section{Parser and Algorithm}

The parser takes input from sentences that are morphologically analysed and Parts of Speech (POS) tagged. Telugu morphological analyzer and POS tagger (Garapati 1999) are used as pre-processing tools. POS tagger helps in selecting the best possible morphological analysis of each word. The parser is built following the Indian theories of verbal cognition where three factors viz. ākānks $\bar{a}$ (expectancy), yōgyata (meaning compatibility), and sannidhi (proximity) are used. We model the parser as a tree where the nodes of a tree correspond to a 
word and the edges between nodes correspond to a relation between the corresponding words. For instance, the parsed tree of the example (1) is provided as below:

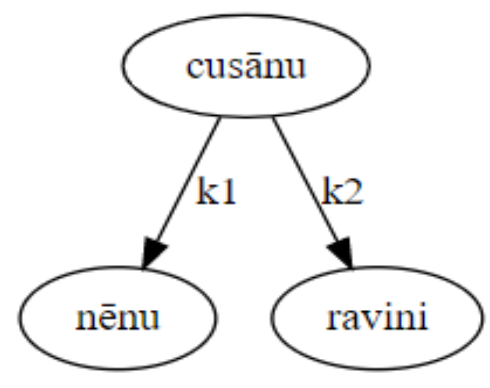

Fig-2 Parsed tree for example (1)

The basic algorithm for parsing which is followed is given below (Kulkarni 2019)

1. Define one node each corresponding to every word in a sentence

2. Establish directed edges between the nodes, if there is either a mutual or unilateral expectancy $(\bar{a} k \bar{a} n k s \bar{a})$ between the corresponding words. In order to hypothesize a possible edge between two words, we refer to the expectancies of the verbs and the corresponding vibhaktis and then postulate a possible relation

3. Define constraints, both local on each node as well as global on the graph as a whole. One of these constraints corresponds to sannidhi (Proximity)

4. Use semantic constraints to filter out the meaning-wise non-congruent solutions

5. Extract all possible trees from this graph that satisfy both local and global constraints 
6. Produce the most probable solution as the first solution by defining an appropriate cost function. The cost $\mathrm{C}$ associated with a solution tree is defined as $\boldsymbol{C}=\sum_{e} \boldsymbol{d}_{e} \times$ $\boldsymbol{r}_{\boldsymbol{k}}$ an edge from a word $\mathrm{w}_{\mathrm{j}}$ to a word $\mathrm{w}_{\mathrm{i}}$ with label $\mathrm{k}, \boldsymbol{d}_{\boldsymbol{e}}=$ $|j-i|, r_{k}$ rank of the role with label $\mathrm{k}$. Then the problem of parsing a sentence may be modelled as the task of finding a sub-graph $\mathrm{T}$ of $\mathrm{G}$ such that $\mathrm{T}$ is a Directed Tree (or a Directed Acyclic Graph).

\subsection{Algorithm: An Elaboration}

In this section, we explain steps 2,3 , and 4 of the algorithms in detail. The step- 2 corresponds to the use of lexical semantics of nouns and verbs, step- 3 is the use of constraints, and step-4 is the use of selectional restriction or mutual congruity.

The step-2 of the algorithm deals with the expectancies of verbs and the corresponding vibhaktis which enable the parser to postulate a possible relation. We notice that the mapping of semantic relations to vibhaktis is one-one except for the optional case marking (see Section 2.2), however the reverse mapping viz. vibhakti to semantic relation is not one-one. Case-suffixes as small as 7 (see table-1 and șașthi) in number are used to express around 40 case relations which lead to ambiguity. Ambiguities hence occurred are resolved by augmenting linguistic information such as the lexical semantics of verbs and nouns. (i) Lexical semantics of verbs. The lexical semantics of verbs provides cues in certain cases to disambiguate vibhaktis with their corresponding semantic relation. Consider the examples (8) \& (9)

\begin{tabular}{|l|l|l|l|l|}
\hline 8. & $n \bar{e} n u-\emptyset$ & $v \bar{a}$ di-ki & pustakam & icc- $\bar{a}-n u$ \\
\hline & I.NOM & He-DAT & Book-ACC & Give-PST-1.SG \\
\hline & \multicolumn{4}{|l|}{ "I gave a book to him". } \\
\hline
\end{tabular}


A Rule-based Dependency Parser for Telugu:...

\begin{tabular}{|l|l|l|l|}
\hline 9. & $n \bar{e} n u-\varnothing$ & baḍi-ki & vell- $\bar{a}-n u$ \\
\hline & I-NOM & School-DAT & Go-PST-1.SG. \\
\hline & "I went to the school" \\
\hline
\end{tabular}

The vibhakti $-k i$ is used to express two different relations viz. sampradānā (k4) as in (8) and goal/destination (k2p) as in (9). In such cases, the semantics of the verb is considered to disambiguate the vibhakti. In example (9), the verb belongs to the class of [+motion] hence it has a requirement of $k 2 p$ unlike the example (8). This semantic information is augmented with syntactic rules in order to mark the appropriate relation.

\section{(ii) Lexical Semantics of Nouns}

In some cases, it is the lexical choice of nouns that helps in resolving the ambiguity. For instance, when the vibhakti-ki/-ku is marked with kāla-adhikaranam (k7t) or deśa-adhikaranam $(\mathrm{k} 7 \mathrm{p})$ relation, corresponding nouns should be either place or time denoting terms as in example (10).

\begin{tabular}{|l|l|l|l|l|l|}
\hline 10. & ravi- $\varnothing$ & $\begin{array}{l}\text { padi- } \\
\varnothing\end{array}$ & gaMțalaku & $\begin{array}{l}\text { haidarabādu- } \\
k u\end{array}$ & cērukun-țā- $d u$ \\
\hline & Ravi- & 10 & $\begin{array}{l}\text { Hour- } \\
\text { DAT }\end{array}$ & $\begin{array}{l}\text { Hyderabad- } \\
\text { DAT }\end{array}$ & $\begin{array}{l}\text { Reach-FUT- } \\
\text { NOMG.M }\end{array}$ \\
\hline & & "Ravi will reach Hyderabad at 10'o'clock" \\
\hline
\end{tabular}

Here, the noun expressing time i.e. padi gaMtalu '10 'o clock', and the place i.e. haidarabādu 'Hyderabad' are marked with $k u$, however, they are marked as $\mathrm{k} 7 \mathrm{p}$ and $\mathrm{k} 7 \mathrm{t}$ respectively based on their semantics. In such cases, a list of these terms is maintained as linguistic cues to access the information.

The step-3 of the algorithm is to define local and global constraints. The local constraints used in the parser to postulate the best possible result are given below (Kulkarni 2019): 
Sangeetha P., Parameswari K. \& Amba Kulkarni

1. A node can have one and only one incoming edge.

2. There cannot be more than one outgoing edge with the same label from the same node if the relation corresponds to a kāraka relation.

3. There cannot be self-loops in a graph. In addition to the local constraints, we also use global constraints like sannidhi 'proximity' which is a constraint that restricts crossing of edges. The sample graph satisfying all the above local and global constraints is provided below:

\begin{tabular}{|c|c|c|c|c|c|c|c|}
\hline 11 & $\begin{array}{l}\text { nēnu- } \\
\varnothing\end{array}$ & $\begin{array}{l}\text { prasādu } \\
-t \bar{o}\end{array}$ & rēpu & $\begin{array}{l}\text { madrāsu } \\
-l \bar{o}\end{array}$ & telugu & $\begin{array}{l}\operatorname{sinim} \bar{a} \\
-k i\end{array}$ & $\begin{array}{l}\text { vel- } \\
t \bar{a}-n u\end{array}$ \\
\hline & $\begin{array}{l}\mathrm{I}- \\
\mathrm{NO} \\
\mathrm{M}\end{array}$ & $\begin{array}{l}\text { Prasad- } \\
\text { ASS }\end{array}$ & $\begin{array}{l}\text { tomorro } \\
\text { W }\end{array}$ & $\begin{array}{l}\text { Madras- } \\
\text { LOC }\end{array}$ & $\begin{array}{l}\text { Telug } \\
\mathrm{u}\end{array}$ & $\begin{array}{l}\text { Movie- } \\
\text { DAT }\end{array}$ & $\begin{array}{l}\text { Go- } \\
\text { FUT } \\
- \\
\text { 1.SG }\end{array}$ \\
\hline & $\mathrm{W}$ & o a & vic & $\overline{\text { Prasad }}$ & $\overline{A a d r a}$ & orrow & \\
\hline
\end{tabular}

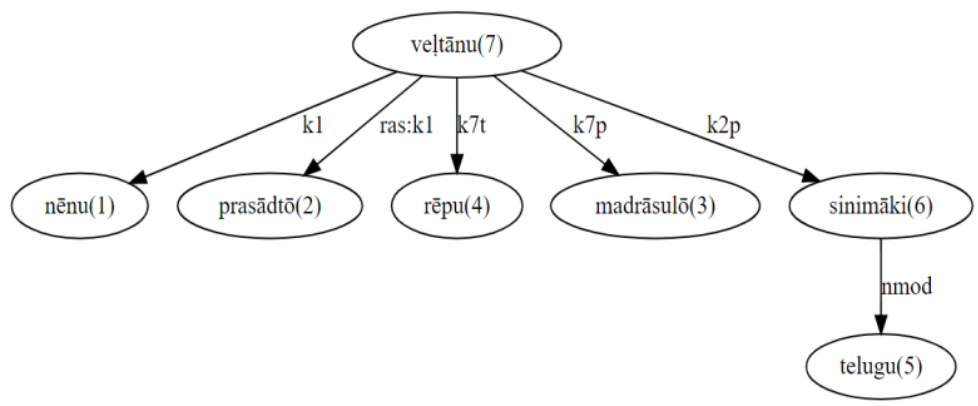

Figure-2 Sample graph for the example (11)

The use of semantic constraints is dealt with in step4 of the algorithm. It is quite important to include semantic constraints in a parser to arrive at the correct solution. For instance, the sentence colourless green ideas sleep furiously (Chomsky 1957) is a syntactically well-formed sentence but semantically ill-formed. The natural language feature which enables the use 
A Rule-based Dependency Parser for Telugu:...

of semantically well-formed constructions is termed as yōgyatā in PG or the selectional restriction in western terminology. The selectional restriction is defined as the semantic constraint imposed on the arguments of verbs. We use selectional restriction of arguments of the verb to prune out the noncongruent solutions and arrive at a single parse. Let us consider the following examples:

\begin{tabular}{|l|l|l|l|}
\hline 12. & tūphānu- $\varnothing$ & illu- $\varnothing$ & $k \bar{u} l c-i M-d i$ \\
\hline & Storm-NOM & House-ACC & destroy-PST-3.SG.N \\
\hline & "The storm destroyed the houses" \\
\hline
\end{tabular}

\begin{tabular}{|l|l|l|l|}
\hline *13. & illu- $\varnothing$ & tüphānu- $\varnothing$ & $k \bar{u} l c-i M-d i$ \\
\hline & & & \\
\hline & house-NOM & storm-ACC & destroy-PST-3.SG.N \\
\hline
\end{tabular}

Both examples (12) and (13) are syntactically well-formed sentences, when yōgyatā is applied, the example (13) stands semantically ill-formed because 'Houses destroying the storm' is a semantically unacceptable sentence. In order to solve such issues, the canonical word order of a language is used as a cue.

The other instance in which we use selectional restriction is to disambiguate kartā and karma in Telugu. When karma is [animate], the vibhakti $\emptyset$ is used which is synonymous with the marker for kartāa. In such cases, two ontological features [+/animate] and [+/- human] could resolve the ambiguity in Telugu as well as in other Indian languages as examined by (Bharati, Akshar; Samar, Husain; Bharat, Ambati; Sambhav, Jain; Dipti, Sharma; \& Rajeev, Sangal 2008). kartā is considered to be higher in its animacy hierarchical order in comparison with karma. Consider the following example: 
Sangeetha P., Parameswari K. \& Amba Kulkarni

\begin{tabular}{|l|l|l|l|}
\hline 14. & $n \bar{e} n u-\emptyset$ & $p \bar{a} t a-\emptyset$ & $p \bar{a} \bar{d}-\bar{a}-n u$ \\
\hline & I.NOM & Song. ACC & sing-PST-3.SG.N \\
\hline & "I sang a song" \\
\hline
\end{tabular}

Here, the verb $p \bar{a} \underline{d} \bar{u}$ 'sing' expects kartā with a semantic feature of [+human] thus, (nēnu) ' $\mathrm{I}$ ' is prioritized over a [animate] entity (i.e. patā) 'song'. These two semantic features proved to be quite helpful in resolving the most ambiguous relation of kartā and karma. As seen earlier, this parser exploits various linguistic information which stands crucial in disambiguating certain cases. In the next section, we present the results, which show the impact of linguistic information used in the parser.

\section{Evaluation of the System}

The parser is evaluated for its Labelled Attachment Score (LAS) and Unlabelled Attachment Score (UAS). In this section, the data used for evaluating parsers is presented followed by the results. Finally, we also present the error analysis and some observations.

\subsection{Data}

The present study selects 453 sentences to test parsers which are extracted from various sources such as (i) Telugu Grammar books viz. telugu vākhyam (Ramarao 1885) and A grammar of modern Telugu (Krishnamurti \& Gwynn 1985) (ii) Random sentences from Telugu corpus ( 3 million words $\left(\right.$ CALTS $^{1}$ ) corpus). The corpus contains sentences with intransitive verbs (223 sentences), transitive verbs (197 sentences), and ditransitive verbs (33 sentences). The sentences covering constructions such as copula, imperative, passive, dubitative,

1 Centre for Applied Linguistics and Translation Studies 
A Rule-based Dependency Parser for Telugu:...

interrogative, non-nominative subjects, reflexive and coordinating noun phrases are noticed.

\subsection{Results}

The results consist of the Unlabelled Attachment Score (UAS) where the dependency tree produced by the parser matches exactly with the tree from the gold data without considering the labels and the Labelled Attachment Score (LAS) which checks if the two relations and labels are correctly matched. Out of 453 sentences, 1043 relations are manually identified and annotated for the evaluation. MALT parser is developed with the data annotated. The rule-based parser produces correct dependency trees for 1001 relations and 969 correct labelled trees. Whereas MALT parser produces 928 relations, out of which 739 relations are correctly labelled. The results are provided in the table- 2 .

\begin{tabular}{|l|l|l|}
\hline Parser type & UAS & LAS \\
\hline Rule-Based Parser & $96.5 \%$ & $92.9 \%$ \\
\hline MALT parser & $89 \%$ & $70.85 \%$ \\
\hline
\end{tabular}

Table 2: Results

Further, the rule-based parser output is analysed with different sentence structures as given in Table-3. The exact match and partial match of sentences are also identified.

\begin{tabular}{|l|l|l|l|l|l|}
\hline Sentence Type & $\begin{array}{l}\text { No. of } \\
\text { sentences }\end{array}$ & $\begin{array}{l}\text { exact } \\
\text { match }\end{array}$ & $\begin{array}{l}\text { partial } \\
\text { match }\end{array}$ & UAS & LAS \\
\hline Intransitive & 223 & 208 & 18 & $97.6 \%$ & $95.5 \%$ \\
\hline Transitive & 197 & 152 & 40 & $97 \%$ & $92.4 \%$ \\
\hline Ditransitive & 33 & 20 & 11 & $86.6 \%$ & $80 \%$ \\
\hline $\begin{array}{l}\text { Copula } \\
\text { constructions }\end{array}$ & 87 & 68 & 16 & $92.5 \%$ & $80 \%$ \\
\hline
\end{tabular}


Sangeetha P., Parameswari K. \& Amba Kulkarni

\begin{tabular}{|l|l|l|l|l|l|}
\hline $\begin{array}{l}\text { Imperative } \\
\text { constructions }\end{array}$ & 25 & 15 & 8 & $68 \%$ & $52 \%$ \\
\hline $\begin{array}{l}\text { Dubitative } \\
\text { constructions }\end{array}$ & 56 & 36 & 18 & $64 \%$ & $56 \%$ \\
\hline $\begin{array}{l}\text { Passive } \\
\text { constructions }\end{array}$ & 33 & 28 & $3 \mathrm{q}$ & $90 \%$ & $81 \%$ \\
\hline $\begin{array}{l}\text { Non-nominative } \\
\text { subject } \\
\text { constructions }\end{array}$ & 66 & 38 & 25 & $48 \%$ & $41 \%$ \\
\hline $\begin{array}{l}\text { Reflexive } \\
\text { constructions }\end{array}$ & 17 & 8 & 7 & $46 \%$ & $33 \%$ \\
\hline $\begin{array}{l}\text { Interrogative } \\
\text { constructions }\end{array}$ & 62 & 48 & 10 & $85 \%$ & $77 \%$ \\
\hline
\end{tabular}

Table-3 Simple sentence structures and results

The parsing errors in these simple sentence structures are studied which help in improving further the rules in the rulebased parser for Telugu.

\subsection{Error Analysis and Observations}

In this section, we discuss certain cases where the rule-based parser fails to provide the appropriate results. The current rule-based parser has a difficulty in dealing with the coordinating noun phrases and with certain pro-drop constructions. As seen in the example (15), the noun phrases gāli nìru 'air and water' are co-ordinating noun phrases, but the linguistic cue to express them as coordination such as either comma (,) (i.e., gāli nìru) or the vowel-length in the end $(g \bar{a} l \bar{l} n \bar{i} r \bar{u})$ are not present. This makes the system identify them wrongly as separate relations. 
A Rule-based Dependency Parser for Telugu:...

\begin{tabular}{|l|l|l|l|l|}
\hline 15. & $\bar{a}$ & prāMtaM-lō & gāli nīru & lēvața \\
\hline & that & place-LOC & water air & be-NEG-QUO \\
\hline & "There is no water or air in that place" \\
\hline
\end{tabular}

Certain verbs in Telugu do not show agreement with the kartā. In example (16), when the verb expresses the mood of possibility with the auxiliary verb vaccu, it does not show agreement with the verb. When the kartā is pro-dropped, the system identifies the karma (i.e. cēpa 'fish'), the zero-marked as kartā. Consider the example below:

\begin{tabular}{|l|l|l|}
\hline 16. & cēpa. $\varnothing$ & tin-a-vaccu \\
\hline & Fish.ACC & eat-INF-POSS \\
\hline & "(subject ) can eat fish" \\
\hline
\end{tabular}

The other two reasons for the failure of the parser in certain cases are due to the wrong output from the pre-processing tools and the lack of a database for the parser. These are handled by correcting the pre-processing output and improving the database (vocabulary). Whereas, in data-driven parsers like MALT, it is difficult to improve the accuracy unless a huge annotated corpus is trained again.

\section{Conclusion}

This paper deals with building a rule-based parser for Telugu experimenting with simple sentences. A discussion on the application of the Pāninian grammatical model to Telugu and the algorithm is provided. This paper explains how the use of two semantic features viz. animacy and humanity enables the unambiguous marking of kartā and karma relations. The 
Sangeetha P., Parameswari K. \& Amba Kulkarni

results show that the rule-based parser proves to be better than the data-driven parser due to the inclusion of linguistic information. Further, the study aims to improve the accuracy of the pre-processing tools and also build the required database for Telugu parsing. The next phase of the study will focus on implementing the rule-based parser for all the sentence structures in Telugu and extending this algorithm to other Indian languages.

Appendix - List of tags used in the Telugu Parser

\begin{tabular}{|c|c|c|}
\hline 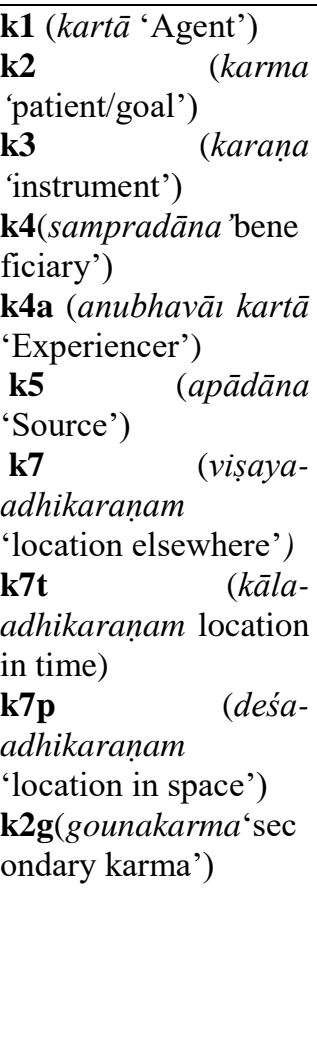 & $\begin{array}{l}\text { r6(șașthī karma 'genitive' ) } \\
\text { rh (hetuh 'reason') } \\
\text { rt (tātparya 'purpose') } \\
\text { k1s(kartṛamānādhikaranam'c } \\
\text { omplement of a kartā') } \\
\text { k2s (karmasamānādhikaranam } \\
\text { 'complement of a karma') } \\
\text { adv (kriyāviśeșaṇnam adverbs) } \\
\mathbf{k} * \mathbf{u}(\text { sādrishya 'similarity') } \\
\text { rd ('direction') }\end{array}$ & $\begin{array}{l}\text { ras-k* } \\
\text { (upapada sahak } \\
\text { ärakatwa } \\
\text { 'associative') } \\
\text { case ('for } \\
\text { postpositions') } \\
\text { det ('determiner') } \\
\text { enm(enumerato } \\
\text { r (number } \\
\text { words)) } \\
\text { jjmod('adjectiv } \\
\text { e modifier' } \\
\text { lwg('local } \\
\text { word grouping) } \\
\text { nmod ('noun } \\
\text { modifier') } \\
\text { r6v ('verb and } \\
\text { noun relation') } \\
\text { rsym ('symbols) } \\
\text { title ('titles of } \\
\text { names') } \\
\text { vmod ('verb } \\
\text { modifier') }\end{array}$ \\
\hline
\end{tabular}


A Rule-based Dependency Parser for Telugu:...

\section{References}

Ambati, Bharat RAm; Phani GAdDE \& Karan Jindal. 2009. Experiments in Indian Language Dependency Parsing. Proceedings of the ICON09 NLP Tools Contest: Indian Language Dependency Parsing. 32-37.

Bharati, Akshar \& Rajeev SAngal. 1993. Parsing Free Word Order Languages in the Paninian Framework. 31st Annual Meeting of the Association for Computational Linguistics. 105-111.

BHARATI, AKSHAR, VinEET ChatTANYA, RAJEEV SANGAL \& K. V. RAMAKRISHNAMACHARYULU. 1995. Natural Language Processing: A Paninian Perspective. New Delhi: Prentice Hall of India.

BHARATI, AKSHAR, SAMAR Husain, BHARAT AMBATI, Sambhav Jain, Dipti Sharma \& Rajeev Sangal. 2008. Two Semantic Features Make All the Difference in Parsing Accuracy. Proceedings of ICON 8.

Bharati, Ambati, Dipti Misra Sharma, Samar Husain, LaKshmi BaI, RafiYa Begum \& Rajeev SANGal. 2009. AnnCorra: TreeBanks for Indian Languages, Guidelines for Annotating Hindi TreeBank (version-2.0). LTRC. Hyderabad: IIIT Hyderabad.

BRESNAN, JOAN. 1982. Control and Complementation. Linguistic Inquiry 13(3). 343-434. http://www.jstor.org/stable/4178286 (Accessed 2nd June 2021).

CHOMSKY, NoAm. 1957. Syntactic Structures ( $2^{\text {nd }}$ edition). Mouton de Gruyter: The Hague.

GARAPATI, UMA MAHESHWAR RAO. 1999. Morphological Analyzer for Telugu. (Electronic form). Hyderabad: University of Hyderabad.

GARAPATI, UMA MAHESHWAR RAO., RAJYARAMA KOPPAKA \& SRINIVAS ADDANKI. 2012. Dative case in Telugu: A Parsing 
Sangeetha P., Parameswari K. \& Amba Kulkarni

Perspective. Proceedings of the Workshop on Machine

Translation and Parsing in Indian Languages. 123-132.

Gatla, Praveen. 2019. Dependency Parsing for Telugu Using Data-driven Parsers. Language in India 19(1). 185197.

Gazdar, Gerald, Ewan Klein, Geoffrey K. Pullum, \&

IVAN A. SAG. 1985. Generalized Phrase Structure

Grammar. Cambridge, MA: Harvard University Press.

Husain, SAMAR. 2009. Dependency Parsers for Indian

Languages. Proceedings of ICONO9 NLP Tools Contest:

Indian Language Dependency Parsing.

KRISHNAMURTI, BH. \& J. P. L. GWYNN. 1985. A Grammar of

Modern Telugu. New Delhi: Oxford University Press.

Kanneganti, SilPa, Himani Chaudhry \& Dipti MisRa

SHARMA. 2018. Comparative Error Analysis of Parser

Outputs on Telugu Dependency Treebank. In Gelbukh A.

(ed.), Computational Linguistics and Intelligent Text Processing. CICLing 2016. Lecture Notes in Computer Science 9623. Springer Cham. https://doi.org/10.1007/9783-319-75477-2_28.

Kesidi, Sruthilaya Reddy, Prudhvi Kosaraju, Meher

ViJAY \& SAMAR Husain. 2013. Constraint based Hybrid Dependency Parser for Telugu. Hyderabad: International Institute of Information Technology Hyderabad doctoral dissertation.

Kumari, B. Venkata Seshu \& Ramisetty Rajeshwara

RAO. 2015. Improving Telugu Dependency Parsing Using Combinatory Categorial Grammar Supertags. ACM Transactions on Asian and Low-Resource Language Information Processing (TALLIP) 14(1), 1-10.

Kumari, B. Venkata SEShU \& RAMISETTY Rajeshwara RAO. 2017. Telugu Dependency Parsing Using Different Statistical Parsers. Journal of King Saud UniversityComputer and Information Sciences 29(1). 134-140. 
A Rule-based Dependency Parser for Telugu:...

KULKARNI, AMBA SHEETAL POKAR \& DEVANAND SHUKL. 2010. Designing a Constraint-based Parser for Sanskrit. International Sanskrit Computational Linguistics Symposium. 70-90.

KULKARNI, AmBA., \& K. V. RAMAKRISHNAMACHARYUlU. 2013. Parsing Sanskrit Texts: Some Relation Specific Issues. Proceedings of the 5th International Sanskrit Computational Linguistics Symposium.

KulKarni, AmBA. 2013b. A Deterministic Dependency Parser with Dynamic Programming for Sanskrit. Proceedings of the Second International Conference on Dependency Linguistics (DepLing 2013). 157-166.

KULKARNI, AmBA. 2019. Sanskrit Parsing Based on the Theories of Sabdabodha. Indian Institute of Advanced Study, Shimla and DK Publishers (P) Ltd.

NAgARAJU, B., N. MANGATHAYARU \& B PADMAJA RANI. 2016. Dependency Parser for Telugu Language. ICTCS '16: Proceedings of the Second International Conference on Information and Communication Technology for Competitive Strategies. 1-5.

Nallani, Sneha, Manish Shrivastava, M., \& Dipti Mishra Sharma. 2020. A Fully Expanded Dependency Treebank for Telugu. Proceedings of the WILDRE5-5th Workshop on Indian Language Data: Resources and Evaluation. 39-44.

Nallani, Sneha, Manish Shrivastava, M., \& Dipti Mishra Sharma. 2020b. A Simple and Effective Dependency Parser for Telugu. Proceedings of the 58th Annual Meeting of the Association for Computational Linguistics: Student Research Workshop. 143-149.

NiVRE, JOAKIM .2000. Statistical Parsing. Handbook of Natural Language Processing 2. 525-543.

PATEL PREETI K. 2010. Vibhakti Divergence Between Sanskrit and Hindi. Hyderabad: University of Hyderabad dissertation. 
Sangeetha P., Parameswari K. \& Amba Kulkarni

Pollard, Carl Jesse \& IVAN A. Sag. 1994. Head-driven Phrase Structure Grammar. Chicago: University of Chicago Press.

RAma, TARAKA \& Sowmya, VajJala. 2018. A Dependency Treebank for Telugu. English Conference Papers, Posters and Proceedings 8. https://lib.dr.iastate.edu/engl_conf/8.

RAMARAO, CheKurI. 1885. Telugu Vākyam. Hyderabad: AP Sahitya Academy.

VEMPATY Chaitanya, VisWANATHA NAIDU, SAMAR HusAin, RAVI KIRAN, LAKSHMI BAI, DiPTI Mishra ShARMA \& RAJEeV SANGAL. 2010. Issues in Analyzing Telugu Sentences towards Building a Telugu Treebank. In Gelbukh A. (ed.), Computational Linguistics and Intelligent Text Processing. CICLing 2010. Lecture Notes in Computer Science 6008. Berlin, Heidelberg: Springer. https://doi.org/10.1007/978-3-642-12116-6_5.

\section{Cite This Work:}

P., Sangeetha, Parameswari K. \& Amba Kulkarni. A Rule-based Dependency Parser for Telugu: An Experiment with Simple Sentences. Translation Today, Vol. 15(1). 123144. DOI:10.46623/tt/2021.15.1.ar5 